\title{
LA PARADOJA DE LOS «IMPERATIVOS CONTRARIOS-AL-DEBER»: UNA MUESTRA DE LA EVOLUCIÓN DE G. H. VON WRIGHT
}

1

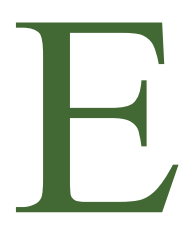

ntre las paradojas de la lógica deóntica existe un grupo de especial importancia por su capacidad para poner en tela de juicio la consistencia de los sistemas standard de lógica deóntica. Estoy haciendo referencia a las «paradojas de la obligación derivada», basadas en la formalización de la noción de compromiso presentada por Von Wright en 1951, según la cual la proposición que afirma que la ejecución de «p» nos compromete a ejecutar «q» puede ser simbolizada así: $\mathrm{O}(\mathrm{p}>\mathrm{q})^{1}$. Muy pronto se hizo evidente que la formalización en ese sentido de la noción de compromiso entrañaba consecuencias paradójicas, como se demuestra a continuación:

$$
[1] \mathrm{P}(\mathrm{p} \vee \mathrm{q}) \leftrightarrow \mathrm{Pp} \vee \mathrm{Pq}
$$

Esta base axiomática del sistema standard de lógica deóntica construido por Von Wright en su artículo «Deontic Logic» (en adelante llamaremos al mencionado sistema SDL) equivale, teniendo en cuenta la interdefinibilidad de los operadores deónticos, a

$$
\text { [2] } \mathrm{O}(\mathrm{p} \& \mathrm{q}) \leftrightarrow \mathrm{Op} \& \mathrm{Oq}
$$

De este axioma se deduce, por transitividad,

$$
\text { [3] Op } \leftrightarrow \mathrm{O}(\mathrm{p} \vee \mathrm{q}) \& O(p \vee-q)
$$

${ }^{1}$ Von Wright, Georg H., Deontic Logic, Mind, núm. 60, 1951, págs. 3 y sigs. Existe trad. cast. de J. Rodríguez Marín, Lógica Deóntica, Teorema, Valencia, 1979, págs. 25-47. 
De [3] se sigue:

$$
\text { [4] } \mathrm{Op}>\mathrm{O}(\mathrm{p} \vee \mathrm{q})
$$

A través de un proceso similar inferimos:

$$
\text { [5] O - p > O (-p v q) }
$$

Y conforme al propio concepto de implicación, [5] equivale a:

$$
[6] \mathrm{O}-\mathrm{p}>\mathrm{O}(\mathrm{p}>\mathrm{q})
$$

De acuerdo con [6], si hacer «p» está prohibido, al hacer «p» nos comprometemos a hacer cualquier otra cosa, lo cual parece que intuitivamente contradice la noción de compromiso formalizada como $\mathrm{O}(\mathrm{p}>\mathrm{q})$. [6] es la fórmula deóntica análoga a la que representa en lógica formal una de las paradojas de la implicación estricta: aquella que afirma que una proposición falsa implica cualquier otra proposición. Aunque, como bien señalaron McLaughlin y el propio Von Wright, la paradoja deóntica parece ser de mayor gravedad. $\mathrm{Si}$ «p» es una proposición falsa, nunca estaremos obligados a aceptarla, ni mucho menos a aceptar sus consecuencias. Por contra, podemos realizar actos prohibidos que según el SDL nos colocan en la absurda situación de deber realizar cualquier otro acto ${ }^{2}$.

Reflexionemos a continuación sobre la siguiente cadena de enunciados:

[A] Debe ser el caso que socorramos llevándolo al hospital a todo accidentado grave que encontremos

[B] Debe ser el caso que si cumplimos [A] ignoremos las señales de tráfico con tal de llegar rápido al hospital.

[C] Si no cumplimos [A] debemos no ignorar las señales de tráfico.

[D] No cumplimos [A].

Podemos expresar formalmente estos enunciados (utilizando «p» como «socorremos llevándolo al hospital a todo accidentado grave que encontramos, $\mathrm{y}$ «q» como «ignoramos las señales de tráfico con tal de llegar rápido al hospital»):

${ }^{2}$ Véase McLaughlin, R. N., Deontic logic and conditional obligation, Mind, núm. 82, 1973, págs. 207 y sigs., y Von Wright, Georg H., On the Logic of Norms and Actions, vol. New Studies in Deontic Logic, ed. de R. Hilpinen, Reidel, Dordrecht, 1981, pág. 7. 


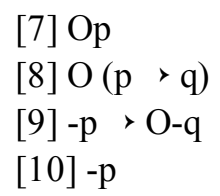

-p > O -q y -p implican, por «modus ponens», O-q. No habría nada de extraño en ello si no fuera porque podemos inferir también Oq de [7]-[10], y ello en base a que, conforme al SDL, Op \& O $(\mathrm{p}>\mathrm{q})>\mathrm{Oq}$ es una verdad lógica. En palabras de Von Wright (1951), es un complejo molecular válido por razones puramente formales, aunque no sea la aplicación de un esquema válido para «cualquier» oración, deóntica o no. Op es una abreviatura de $-\mathrm{P}-\mathrm{p}, \mathrm{O}(\mathrm{p}>\mathrm{q})$ de $-\mathrm{P}(\mathrm{p} \&-\mathrm{q})$, y Oq de -P -q. Obtenemos por tanto -P - $\mathrm{p} \&$ $-P(p \&-q)>-P$ - $q$. La forma normal disyuntiva de $-p$ en términos de $p$ y q es (p \& q) v (-p \& -q). La forma normal de $\mathrm{p} \&$-q es $\mathrm{p} \&$-q. La forma normal de -q es ( $\mathrm{p} \vee \mathrm{q}$ ) $\mathrm{v}(-\mathrm{p} \&-\mathrm{q})$. Por consiguiente, los constituyentes del complejo molecular en cuestión son $P(p \&-q), P$ (-p \& q) y $\mathrm{P}(-\mathrm{p} \&$ \& $)$, y en base a ellos es posible construir la tabla de verdad según la cual siempre es el caso que $\mathrm{Op} \& \mathrm{O}(\mathrm{p}>\mathrm{q})>\mathrm{Oq}^{3}$.

Quizá a primera vista podamos achacar la paradoja a la desigual forma lingüística de [B] y [C], que repercute en [8] y [9]. Podríamos así pensar que [B] equivale a:

${ }^{3}$ Von Wright, Georg H., Deontic Logic, cit., págs. 11 y sigs. Diez años antes de salir a la luz «Deontic Logic», Alf Ross había criticado la validez de Op \& O (p > q) > Oq, Así, la inferencia

[a] Ámate a ti mismo

[b] Ama a tu prójimo como a ti mismo (si te amas a ti mismo, ama también a tu prójimo)

[c] Ama a tu prójimo

no es correcta, pues sólo si se cumple la premisa [a], entonces es cierto [c] en virtud de [b]. Ross considera extraño que autores como Jorgensen, Grelling, Grue-Sorensen o Rand no hubieran percibido la mencionada incorrección (ROSS, Alf, Imperatives and Logic, Theoria, VII, 1941, págs. 53-7 1. Reeditado en Philosophy of Science, XI, 1944, págs. 30-46. Cito por la trad. italiana de G. Ferrari y R. Guastini: Imperativi e logica, vol. Critica del diritio e analisi del linguaggio, ed. de A. Febbrajo y R. Guastini, Il Mulino, Bolonia, 1982, págs. 90 y 91). En el ejemplo que presentamos parece todavía más evidente que el deber de socorrer acompañado del deber de ignorar las señales de tráfico en el caso de que llevemos al accidentado al hospital no puede implicar que, incluso incumpliendo el primer deber, estemos obligados a ignorar las señales de tráfico. 
[B*] Si cumplimos [A] debemos ignorar las señales de tráfico con tal de llegar rápido al hospital.

[B*] se formalizaría entonces así:

$[11] \mathrm{p}>\mathrm{Oq}$

$\mathrm{O}$, alternativamente, podríamos modificar la forma externa lingüística de [C]:

$\left[\mathrm{C}^{*}\right]$ Debe ser el caso que si no cumplimos [A] no ignoremos las señales de tráfico.

[C*] se formalizaría entonces así:

$[12 *]$ O $(-\mathrm{p}>-\mathrm{q})$

[7]-[10] sería entonces sustituida por esta secuencia:

[7] Op

[11] $\mathrm{p}>\mathrm{Oq}$

[9] $-\mathrm{p}>\mathrm{O}-\mathrm{q}$

[10]-p

O bien por esta otra:

[7] Op

$[8] \mathrm{O}(\mathrm{p}>\mathrm{q})$

[12] O (-p > -q)

[10] -p

Empleando una de estas dos últimas secuencias evitaríamos deducir a la vez Oq y $\mathrm{O}$-q. Sin embargo, como bien puso de manifiesto B. Hansson [12] es una consecuencia posible de [7], aunque [C*] no es consecuencia de [A], y [11] es una consecuencia posible de [10] aunque $\left[\mathrm{B}^{*}\right]$ no es consecuencia de [D]. La obligación de $[\mathrm{C}]$ es de diferente naturaleza a la de [A], ya que expresa un deber secundario -para el caso de que el deber primario que se infiere de [A] no sea cumplido- de difícil formalización en $\mathrm{SDL}^{4}$.

${ }^{4}$ Hansson, Bengt, Ant Analysis of Some Deontic Logics, Nous, núm. 3, 1969, págs. 384 y sigs. Reeditado en el vol. Deontic Logic: Introductory and Systematic Readings, ed. de R. Hilpinen, Reidel, Dordrecht, 2. ' ed., 1981, págs. 132 y sigs. 
En conclusión, de la cadena consistente de expresiones lógicas [7]-[10] se derivan a la vez $\mathrm{O}$-q y Oq, lo cual, teniendo en cuenta que Oq implica -O -q, es contradictorio. Esta es la paradoja de los «imperativos contrarios-al-deber», que procede de la paradoja de la obligación derivada a la que antes aludimos. Tales «imperativos contrarios-al-deber», que deben su nombre al hecho de que entrañan la obligación de hacer algo en virtud de haber incumplido un deber previo, no parecen poderse formalizar en SDL.

2. El objeto del presente trabajo es exponer de forma ordenada las soluciones ofrecidas para evitar la paradoja de los «imperativos contrarios-al-deber». Pienso que la primera distinción que cabe realizar es la que diferencia, por un lado, a aquel tipo de propuestas que básicamente siguen siendo fieles al SDL, sin cuestionarlo de una forma generalizada aunque reclamando modificaciones en alguno de sus principios fundamentales, Me referiré preferentemente a los trabajos de Von Wrihgt «Norm and Action» (1963), «A New System of Deontic Logic» (1964) y «A Correction to a New Systems of Deontic Logic» (1965), así como a las aportaciones de D. Follesdal y R. Hilpinen («Deontic Logic: An Introduction», 1971) y de B. Hansson («An Analysis of Some Deontie Logics», 1969). Por otro lado, mencionaré aquellas otras soluciones que no se apoyan en la necesidad de reformar parcialmente el SDL, sino que por el contrario hacen hincapié en aspectos que afectan a la propia naturaleza de la lógica deóntica, lo que no deja de ser una clara prueba de la trascendencia de paradojas como la que estudiamos. En concreto, aludiré a la posición adoptada por Von Wright a partir de finales de los años sesenta, en la línea de conceder importancia a la precisión en el uso lingüístico de determinados términos deónticos, así como a la propia estructura lingüística de los enunciados deónticos, algunas veces con la forma de «reglas ideales» («Sein-Sollen») y otras veces con la forma de «reglas de conducta» («Tun-Sollen») («Deontic Logic and the Theory of Conditions», 1968; «Deontic Logic Revisited», 1973; «On the Logic of Norms and Actions», 1981; «Norms, truth and logic», 1983). Asimismo, debo incluir en este segundo apartado propuestas como la de Castañeda, quien trata de llegar aún más lejos a la hora de recalcar la importancia del análisis riguroso del lenguaje común empleado en lógica deóntica («The Paradoxes of Deontic Logic: The Simplest Solution to All of Them in One Fell Swoop», 1981). Comentaré también las líneas teóricas tendentes a establecer una «relativización temporal» o una «gradualización material» de los conceptos deónticos básicos (L. Aqvist y J. Hoepel- 
man, «Some Theorems About a ?Tree” System of Deontic Tense Logic», 1981; L. Peña, «Un enfoque no-clásico de varias antinomias deónticas», 1988).

3. En «A New System of Deontic Logic», Von Wright reconoció que la percepción de la paradoja de los «imperativos contrarios-al-deber» le incitó definitivamente a construir un nuevo sistema de lógica deóntica. En el SDL, considerando Op como la expresión de un deber primario, $\mathrm{O}(-\mathrm{p}>\mathrm{q})$ no podía ser la formalización de un «imperativo contrario-al-deber» para el caso de que incumpliéramos nuestro deber primario. Esto resultaba fácil de explicar: Op $\leftrightarrow([\mathrm{p} v \mathrm{q}] \&[\mathrm{p} \mathrm{v}-\mathrm{q}])$ es un teorema del SDL. Conforme al axioma $\mathrm{O}(\mathrm{p} \& \mathrm{q}) \leftrightarrow \mathrm{Op} \& \mathrm{Oq}$, y teniendo en cuenta que cualquier variable de un axioma o de un teorema podía sustituirse por otra variable o por un compuesto molecular de variables, $O([p \vee q] \&[p \vee-q]) \leftrightarrow O(p \vee q) \& O(p \vee-q)$ es un teorema, como también lo son, por «modus ponens», $\mathrm{Op}>\mathrm{O}(\mathrm{p} \vee \mathrm{q})$ y $\mathrm{Op}>\mathrm{O}(-\mathrm{p}>\mathrm{q})$. Es decir, «cualquiera que sea el estado de cosas que ?q" describa», debemos hacer «q» si incumplimos el deber de hacer «p», lo cual choca evidentemente con la noción de «imperativos contrarios al-deber», que obligan a realizar un acto o un conjunto de actos -no cualquier cosa- si dejamos de cumplir el deber primario 5 .

Ahora bien, del hecho de la inadecuación de la fórmula $\mathrm{O}(-\mathrm{p}>\mathrm{q})$ para expresar un «imperativo contrario-al-deber» en el SDL no se puede directamente inferir la incapacidad del sistema del 51 para albergar dicha clase de imperativos. Una propuesta alternativa que el propio Von Wright estudió fue $-\mathrm{p}>\mathrm{Oq}$, entendido como hipotético «imperativo contrario-al-deber» condicionado al incumplimiento de Op:

Supongamos que Op si se cumple. Podemos entonces afirmar que $\mathrm{p}>(-\mathrm{p}>\mathrm{Oq})$. Es decir, el cumplimiento de Op implica que, en el caso de que Op se hubiera incumplido -en el caso de que «p» fuera falso- debería ser que «q», «cualquiera que fuera el estado de cosas que ?q" describiera», incluso si ese estado de cosas fuera -q. Pensemos en un padre que ordena a su hijo que dedique la tarde al estudio (Op). También le ordena que, si no estudia, le ayude a limpiar su coche $(-p>O q)$, dejándole claro que si cumple su obligación de estudiar no deberá ayudarle a limpiar su coche. Este último enunciado se podría expresar así: -(-p > O -q). Pero -apunta Von Wright-

${ }^{5}$ Von Wright, Georg H., A New System of Deontic Logic, Danish Year book of Philosophy, núm. 1, 1964, págs. 173-182. Reeditado en el vol. cit. Deontic Logic: Introductory and Systematic Readings, págs. 105-115. 
-(-P > O -q) implica -p, puesto que lo falso implica cualquier cosa. Por consiguiente, llegamos a la conclusión absurda de que si se niega que se deba cumplir el «imperativo contrario-al-deber» si se ha cumplido el deber primario, de ello se sigue que se ha incumplido el deber primario ${ }^{6}$.

Existe otra razón contra el empleo de $-\mathrm{p}>\mathrm{Oq}$ como fórmula que represente en el SDL un «imperativo contrario-al-deber», y que en «A New System of Deontic Logic» Von Wright únicamente sugiere. Esta segunda razón es que -p > Oq no es una fórmula bien formada del SDL. Cerca de veinte años después, en «Norms, truth and logic», sí profundizará en ello al advertir la necesidad de aclarar si, en -p > Oq, Oq se interpreta descriptiva o prescriptivamente. En el primer caso, $-\mathrm{p}>$ Oq constata simplemente el hecho de que, si no es que «p», existe una norma según la cual debe ser que «q». Pero esta aserción no puede ser desde luego una norma condicional. En el segundo caso, nos hallamos ante una expresión sin sentido en el discurso significativo, puesto que se compondría de un elemento descriptivo y de un elemento prescriptivo enlazados mediante una conectiva veritativa. Sólo elípticamente podría concebirse que $p>$ Oq alude a cómo las cosas deberían ser. Incluiría implícitamente un operador deóntico de segundo orden, por lo que realmente la expresión sería $\mathrm{O}(\mathrm{p}>\mathrm{Oq})$, con lo que volveríamos a encontrarnos con los mismos problemas que nos hicieron desechar $\mathrm{O}(\mathrm{p}>\mathrm{q})^{7}$.

Parece acertada la apreciación de Follesdal y Hilpinen en el sentido de destacar que la noción de deber propia de los «imperativos contrarios-al-deber» no puede expresarse en el SDL por la razón de que este sistema sólo contempla un operador deóntico perteneciente a los mundos deónticamente posibles. En su teoría semántica de las modalidades deónticas los autores interpretan Of en el sentido de que «f» es verdad en todos los mundos deónticamente perfectos o en todas las alternativas ideales a nuestro «mundo actual». Op y $\mathrm{O}(\mathrm{p}>\mathrm{q})$ son enunciados de la forma de Of, ya que en todo mundo ideal es verdad que «p» y que «q». Pero no ocurre lo mismo con -p > O -q, puesto que -q sólo es verdad en los mundos en los que es verdad que -p, y ello exigiría otro operador deóntico, que bien podría ser $\mathrm{O}_{-\mathrm{p}}^{8}$.

${ }^{6}$ Ibid., págs. 108 y 109.

${ }^{7}$ Von Wright, Georg H., Norms, truth and logic, vol. Practical Reason. Philosophical Papers I, Basil Blackwell, Oxford, 1983, págs. 130-209. Utilizo la trad. italiana de G. Pezzini (revisada por A. A. Martino): Norme, verita e logica, Informatica e Diritto, núm. 9, septiembre-diciembre, 1983, pág. 29.

${ }^{8}$ Follesdal, Dagfirm y Hilpinen, Risto, Deontic Logic: an Introduction, vol. cit. Deontic Logic: Introductory and Systematic Readings, pág. 26. 
4. En una línea similar a la que acabamos de referirnos, Von Wright presentó desde finales de los años cincuenta un sistema de modalidades deónticas diádicas cuyo objetivo consistía en superar la unilateralidad argumental de los operadores monádicos. Con los operadores diádicos se expresaban, implícita o explícitamente, relaciones entre dos argumentos que constituían el antecedente y el consecuente de una nueva forma de implicación, la implicación deóntica. Sánchez-Mazas ha enumerado las principales formas adoptadas por esta implicación deóntica:

1) «La norma $n_{h}$ ordena (obliga a) ejecutar la acción $a_{i} \cdot$ »

2) «La ejecución de la acción $a_{h}$ compromete (obliga implícitamente) a ejecutar la acción $\mathrm{a}_{\mathrm{i} .} . »$

3) «El estado de cosas B obliga a pasar al estado de cosas A.»

4) «La omisión de la acción $\mathrm{a}_{\mathrm{i}}$ implica (trae consigo) una sanción S.»

En un sistema diádico las acciones no son obligatorias en sí mismas, sino que es preciso determinar en qué condiciones lo son, en qué universo normativo o fáctico lo son'. Ya en «Norm and Action» Von Wright estructuraba los pilares de su nuevo sistema, fundado en tres estratos: 1) La lógica clásica de las Proposiciones, basada en un estudio formal de las expresiones $p, q, \ldots ; 2)$ La lógica del Cambio, basada en un estudio formal de las expresiones $\mathrm{T}$ (el suceso descrito por pTq es una transformación de un estado inicial de cosas descrito por «p» a un estado final de cosas descrito por «q»); 3) La Lógica de la Acción, basada en un estudio formal de las expresiones df (d [-pTp]) significa que algún agente, en alguna ocasión, provoca el estado de cosas descrito por «p», inexistente hasta entonces; f (-pTp) significa que algún agente, en alguna ocasión, se abstiene de provocar el estado de cosas descrito por «p») ${ }^{10}$. La teoría lógica de la acción condicionada constituía una extensión de la Lógica de la Acción. Introducía el símbolo «/», de forma que la expresión / elemental de (pTp) / (qTq) describiera una acción genérica que es ejecutada por un agente de forma que en alguna ocasión, en que el estado de cosas descrito por «q» se da y permanece independientemente de la acción, impide que desaparezca el estado des-

${ }^{9}$ Sánchez-Mazas, Miguel, Cálculo de las normas, Ariel, Barcelona, 1973, págs. 52 y 53.

${ }^{10}$ Von Wright, Georg H., Norm and Action, Routledge and Kegan Paul, Londres, 1963. Utilizo la trad. cast. de P. García Ferrero: Norma y Acción, Tecnos, Madrid, 1979, págs. 47 y sigs., y 73 y sigs. 
crito por «p». O (d [pTp]/[qTq]) es, por consiguiente, un mandato cuyo contenido es la acción descrita por d (pTp) y su condición de aplicación es el cambio descrito por pTp \& $\mathrm{qTq}^{11}$.

¿Cómo se podría formalizar, conforme a este nuevo sistema, la noción de compromiso? Von Wright destaca que esta cuestión está en directa relación con la propia noción de lógica deóntica diádica. El mandato $\mathrm{O}(\mathrm{d}[-\mathrm{pTp}] /[\mathrm{qTq}])$ ordena «p» si «q» se da y permanece. Pero si «q» se pudiera producir mediante acción y, de hecho, un agente hace -qTq, ello compromete a hacer «p». Aunque en principio parece que la noción de compromiso, al referirse a dos distintas ocasiones de actuación, exigiría un sistema «temporalizado», este inconveniente no aparecería concibiendo el compromiso como «acto-implicación», que significaría la transformación de p \& -q en p \& q o en -p \& q o en -p \& -q. Se expresaría entonces Od ( $p \&-q T p>q)$. Conforme a esta idea de acto-implicación Von Wright estudia sustituir la antigua fórmula del compromiso $O(p>q)$ por:

[13] O (d [-pTp] \& d [-qTq] v f [-pTp] \& d [-qTq] v f $[-\mathrm{pTp}] \& \mathrm{f}[-\mathrm{qTq}])$

Es decir, es obligatorio que sea el caso que, o bien (p \& q), o bien (-p \& q), o bien (-p \& -q). O lo que es lo mismo, que no sea (p \& -q). Pero O- (p \& -q) vuelve a tropezar con el efecto paradójico de ser a la vez consecuente de $\mathrm{O}-\mathrm{p}$ y de Oq en virtud de las paradojas de la obligación derivada ${ }^{12}$. La única forma de superar esos efectos paradójicos es -concluye Von Wright en «Norm and Action»-incorporar adecuadamente la noción de permisión a la fórmula del compromiso en el siguiente sentido:

[14] O (d [-pTp] \& d [-qTq] v f [-pTp] \& d [-qTq] v f

$[-p T p] \& f[-q T q]) \& P(d[-p T p] /[-q T-q] \& P f$

$[-\mathrm{qTq}] /[-\mathrm{pT}-\mathrm{p}])$

Abreviando, [14] se puede expresar así:

[15] O- (p \& -q) \& P (p/ -q) \& P (-q/ -p)

[15] implica $P(-p /-q)$ y también $P(q /-p)$. El compromiso puede ahora definirse así: «El hecho de que esté prohibido hacer una determinada cosa y abstenerse de otra determinada

${ }^{11}$ Ibid., págs. 179 y sigs.

${ }^{12}$ Ibid., págs. 191 y sigs. 
cosa en alguna ocasión, da lugar a un compromiso para hacer la segunda cosa, si se hace la primera cuando, y solamente cuando, el agente es normativamente libre de, es decir, tiene permiso para hacer o abstenerse de la primera cosa, y también normativamente libre de, es decir, tiene permiso para hacer o abstenerse de la segunda cosa en la ocasión en cuestión» ${ }^{13}$.

5. No obstante, en «A New System of Deontic Logic» Von Wright se muestra más interesado en perfeccionar su nuevo sistema diádico, en el que parece que confía de cara a la resolución de las paradojas, que en confirmar la corrección de la nueva fórmula del compromiso dependiente del operador deóntico P presentada en «Norm and Action».

En el sistema diádico que se comienza a presentar en 1964 (a partir de ahora NSDL) la expresión atómica $\mathrm{O}$ (p/ q) puede leer se «se debe hacer que ?p" cuando ?q"» o «se debe hacer que ?p" si es el caso que ?q"». «p» y «q» describen posibles estados de cosas. Cuando el mundo es como «q» lo describe, entonces el mundo debe ser como «p» lo describe. De análoga forma, $\mathrm{O}(\mathrm{p} / \mathrm{p})$ significa que el mundo es como debe ser, por lo que implica el deber de que el estado de cosas en cuestión no desaparezca; y $\mathrm{O}(\mathrm{p} / \mathrm{-p})$ significa que se debe hacer que «p» cuando no es el caso que «p», por lo que el estado de cosas en cuestión debe llegar a ser. Aunque las reglas de inferencia del NSDL se heredan del SDL, los nuevos axiomas difieren de los antiguos como consecuencia de la introducción de operadores diádicos ${ }^{14}$ :

$$
\begin{array}{ll}
\mathrm{N} 1 & -(\mathrm{O}[\mathrm{p} / \mathrm{q}] \& \mathrm{O}[-\mathrm{p} / \mathrm{q}]) \\
\mathrm{N} 2 & \mathrm{O}(\mathrm{p} \& \mathrm{q} / \mathrm{r}) \leftrightarrow \mathrm{O}(\mathrm{p} / \mathrm{r}) \& \mathrm{O}(\mathrm{q} / \mathrm{r}) \\
\mathrm{N} 3 & \mathrm{O}(\mathrm{p} / \mathrm{q} \vee \mathrm{r})-\mathrm{O}(\mathrm{p} / \mathrm{q}) \& \mathrm{O}(\mathrm{p} / \mathrm{r})
\end{array}
$$

Si acogemos los axiomas o teoremas del SDL y sustituimos las expresiones atómicas $\mathrm{O}$ que hay en ellos por expresiones atómicas del tipo $\mathrm{O}(-/ \mathrm{t})$ (donde «t» representa una tautología formada por las variables $\mathrm{p}, \mathrm{q}, \mathrm{r}$.... y las conectivas de verdad), las fórmulas obtenidas son teoremas del NSDL. -(Op \& O -p) puede transformarse en - $(\mathrm{O}[\mathrm{p} / \mathrm{t}]$ \& $\mathrm{O}[-\mathrm{p}$ $/ \mathrm{t}])$, y asimismo $\mathrm{O}(\mathrm{p} \& \mathrm{q}) \leftrightarrow \mathrm{Op} \&$ Oq puede transformarse en $\mathrm{O}(\mathrm{p} \& \mathrm{q} / \mathrm{t}) \leftrightarrow \mathrm{O}(\mathrm{p} / \mathrm{t}) \&$ $\mathrm{O}(\mathrm{q} / \mathrm{t})$. A partir de estos dos teoremas se pueden inferir en el NSDL tantos otros como los derivables en el SDL de las respectivas fórmulas citadas ${ }^{15}$.

${ }^{13}$ Ibid., pág. 194.

${ }^{14}$ Von Wright, Georg H., A New System of Deontic Logic, cit., págs. 109 y 110.

${ }^{15}$ Ibid., pág. 111. 
Reflexionemos ahora sobre las importantes consecuencias de los siguientes teoremas del NSDL:

$\mathrm{T} 1 \mathrm{O}(\mathrm{p} / \mathrm{q})>\mathrm{O}(\mathrm{p} v-\mathrm{p} / \mathrm{q})$

$\mathrm{T} 2 \mathrm{O}(\mathrm{p} / \mathrm{q})>\mathrm{O}(\mathrm{p} / \mathrm{q} \&-\mathrm{q})$

T1 se obtiene de N2 y de la equivalencia tautológica $\mathrm{p} \leftrightarrow(\mathrm{p} \vee-\mathrm{p}) \& \mathrm{p}$. De T1 se puede deducir que si ante ciertas circunstancias una cosa es obligatoria, entonces ante esas mismas circunstancias cualquier cosa lógicamente más débil («any logically weaker thing») es también obligatoria. T2 se obtiene de N3 y de la equivalencia tautológica $\mathrm{q} \leftrightarrow(\mathrm{q} \&-\mathrm{q})$ v q. De T2 se puede deducir que si ante ciertas circunstancias una cosa es obligatoria, entonces esta cosa es también obligatoria ante circunstancias lógicamente más fuertes («any logically stronger circumstances») $)^{16}$.

En el último apartado de su artículo de 1964 Von Wright se cuestiona la formalización del compromiso en su NSDL, y admite la posibilidad de la corrección de la expresión $O(q /-p)$ como «imperativo contrario-al-deber» respecto a $O(p / t)$. $O(p / t)$ es una fórmula abreviada de $\mathrm{O}([\mathrm{p} \vee \mathrm{q}] \&[\mathrm{p} \vee-\mathrm{q}] /[\mathrm{p} \& \mathrm{q}] \mathrm{v}[\mathrm{p} \&-\mathrm{q}] \mathrm{v}[-\mathrm{p} \& \mathrm{q}] \mathrm{v}[-\mathrm{p} \&-\mathrm{q}])$. $\mathrm{O}$ $(q /-p)$ es una fórmula abreviada de $O([p \vee q] \&[-p \vee q] /[-p \& q] \vee[-p ~ \&-q])$. Se aprecia perfectamente que $\mathrm{O}(\mathrm{p} / \mathrm{t})$ y $\mathrm{O}(\mathrm{q} / \mathrm{-p})$ no dependen entre sí, ya que dos de los constituyentes de la obligación hipotética no están entre los constituyentes de la obligación categórica. Ahora bien, en opinión de Von Wright esta independencia no significa exactamente que 0 (q /-p) expresa el «imperativo contrario-al-deber» de hacer que «q» en el caso de que el agente haya incumplido su deber primario de hacer «p», puesto que no hay ninguna señal de evidencia en $\mathrm{O}(\mathrm{q} / \mathrm{-p}$ ) que demuestre que el estado de cosas $-\mathrm{p}$ ha sido consecuencia del incumplimiento de una obligación. Pero a pesar de ello la expresión $O(q /-p)$ parece captar la naturaleza de la norma hipotética que obliga a hacer que «q» si es el caso que -p, algo que no consiguen $\mathrm{O}(-\mathrm{p}>\mathrm{q}) \mathrm{ni}-\mathrm{p}>\mathrm{Oq}$. Por consiguiente, se puede afirmar que si la causa de -p es el incumplimiento por parte del agente del deber de hacer «p», entonces $O(q /-p)$ es, al menos para ese agente, un «imperativo contrario-al-deber» ${ }^{17}$.

6. No obstante, un año después, en «A Correction to a New System of Deontic Logic», Von Wright reconoce la existencia de

${ }^{16}$ Ibid., págs. 112 y 113.

${ }^{17}$ Ibid., págs. 114 y 115. 
defectos en su NSLD con posibles repercusiones en la validez de la formalización propuesta de la noción de «imperativos contrarios-al-deber». En concreto, el lógico finlandés admite la posibilidad de demostrar en base a los axiomas del NSLD la implicación contradictoria $\mathrm{O}(\mathrm{p} / \mathrm{q})>\mathrm{O}(-\mathrm{p} / \mathrm{r})$ : la obligación de hacer «p» si es el caso que «q» implica que no hay obligación de no hacer «p» si es el caso que «r». Esto es absurdo por la irrelevancia de -O $(-\mathrm{p} / \mathrm{r})$ respecto a $\mathrm{O}(\mathrm{p} / \mathrm{q})$, pero parece poder demostrarse:

Conforme a la regla de extensionalidad, $\mathrm{O}(\mathrm{p} / \mathrm{q})$ es equivalente a $\mathrm{O}(\mathrm{p} /[\mathrm{q} \& \mathrm{r}] \mathrm{v}[\mathrm{q}$ \& -r]). Según el axioma N3, también es equivalente a $\mathrm{O}(\mathrm{p} / \mathrm{q} \& \mathrm{r}) \& \mathrm{O}(\mathrm{p} / \mathrm{q} \&-\mathrm{r}), \mathrm{y}$, por consiguiente, implica $\mathrm{O}$ (p/q \& r). En efecto, ya observamos que, como consecuencia de T2, si ante ciertas circunstancias una cosa es obligatoria, entonces también lo es ante circunstancias lógicamente más fuertes. Igualmente, tenemos que $\mathrm{O}(-\mathrm{p} / \mathrm{r})>\mathrm{O}(-\mathrm{p} / \mathrm{q} \& \mathrm{r})$, o lo que es lo mismo, que $-\mathrm{O}(-\mathrm{p} / \mathrm{q} \& \mathrm{r})>-\mathrm{O}(-\mathrm{p} / \mathrm{r})$. Y, en virtud del principio de no contradicción $(\mathrm{N} 1), \mathrm{O}(\mathrm{p} / \mathrm{q} \& \mathrm{r})>-\mathrm{O}(-\mathrm{p} / \mathrm{q} \& \mathrm{r})^{18}$. Disponemos, por tanto, de la siguiente cadena de implicaciones:

$$
\begin{aligned}
& {[16] \mathrm{O}(\mathrm{p} / \mathrm{q})>\mathrm{O}(\mathrm{p} / \mathrm{q} \& \mathrm{r})} \\
& {[17] \mathrm{O}(\mathrm{p} / \mathrm{q} \& \mathrm{r})>-O(-\mathrm{p} / \mathrm{q} \& \mathrm{r})} \\
& {[18]-O(-\mathrm{p} / \mathrm{q} \& \mathrm{r})>-0(-\mathrm{p} \& \mathrm{r})}
\end{aligned}
$$

En conclusión:

$$
[19] \mathrm{O}(\mathrm{p} / \mathrm{q})>-\mathrm{O}(-\mathrm{p} / \mathrm{r})
$$

Lo que separará a Von Wright de sus principales críticos será su insistencia en atribuir a N1, y no a N3, la culpa de estas implicaciones contradictorias. La solución residiría en reemplazar N1 por un axioma «esencialmente más débil»:

$$
\mathrm{N} 1{ }^{-}-(\mathrm{O}[\mathrm{p} / \mathrm{q}] \& \mathrm{O}[-\mathrm{p} / \mathrm{q}] \& \mathrm{O}[\mathrm{p} /-\mathrm{q}] \& \mathrm{O}[-\mathrm{p} /-\mathrm{q}])
$$

$\mathrm{N} 1 *$, que no propicia la implicación contradictoria $\mathrm{O}(\mathrm{p} / \mathrm{q})>-\mathrm{O}(-\mathrm{p} / \mathrm{r})$, proviene de la idea de que, al igual que las dos

${ }^{18}$ Von Wright, Georg H., A Correction to a New System of Deontic Logic, Danish Yearbook of Philosophy, núm. 2, 1965, págs. 103-107. Las secciones II, III, IV y V de este artículo se reeditaron en el vol. cit. Deontic Logic: Introductory and Systematic Readings, cit., págs. 115-120. 
unidades deónticas $\mathrm{Op}$ y $\mathrm{O}$-p no pueden ser válidas en un mismo espacio deóntico, tampoco lo pueden ser O (p \& q) y O -(p \& q), lo que, por la distributividad conjuntiva del operador $\mathrm{O}$, significa que tampoco pueden coexistir como válidas en un mismo espacio deóntico $\mathrm{O}$ $(\mathrm{p} \vee \mathrm{q}), \mathrm{O}(\mathrm{p} \vee-\mathrm{q}), \mathrm{O}(-\mathrm{p} \vee \mathrm{q})$ y $\mathrm{O}(-\mathrm{p} \vee-\mathrm{q})$. En un sistema diádico en el que sólo se utilizara una variable, no serían válidas en el mismo espacio deóntico $O(p / p), O(p /-p), O(-p / p)$ y $\mathrm{O}(-\mathrm{p} / \mathrm{-p})$. Es decir, tenemos que:

$[20]-(O[p / p] \& O[p /-p] \& O[-p / p] \& O[-p /-p])$

En virtud de N3, [20] es equivalente a:

$[21]-(O[p / p \vee-p] \& O[-p / p \vee-p])$

Por extensionalidad [21] puede convertirse en [22], que equivale a N1*19.

$$
[22]-(O[p / q v-q] \& O[-p / q v-q])
$$

Von Wright admite una consecuencia evidente de la sustitución de N1 por N1*: la compatibilidad de determinadas situaciones normativas, incompatibles según N1. En efecto, los deberes conflictivos («conflicting duties») $\mathrm{O}$ (p/q) y $\mathrm{O}$ (-p/q), expresamente incompatibles en virtud de $\mathrm{N} 1$, no tienen por qué ser compatibles en virtud de $\mathrm{N} 1 *$ siempre que no coexistan también con $\mathrm{O}(\mathrm{p} / \mathrm{-q})$ y $\mathrm{O}(-\mathrm{p} / \mathrm{-q})$. Es decir, siempre que no afecten a deberes absolutos, incondicionales, categóricos, sino a deberes relativos, condicionales, hipotéticos.

El conflicto de deberes depende de las circunstancias que rodean al agente en cuestión; aparece únicamente ante determinadas circunstancias, que constituyen, en palabras de Von Wright, un «predicamento» («predicament») $)^{20}$. El ejemplo típico de predicamento es la promesa de hacer algo prohibido, que conduce al dilema de incumplir una de estas dos normas: la que obliga a cumplir la promesa y la que prohíbe hacer justo aquello que se ha prometido. Von Wright advierte que el predicamento no es independiente de sus circunstancias constituyentes, sino que surge gracias al acto del agente, por lo que este acto está prohibido. Ya en 1951, en «Deontic Logic» y en «An Essay in Modal Lo-

${ }^{19}$ Ibid., págs. 116 a 118.

${ }^{20}$ Ibid., págs. 118 y 119. 
gic», Von Wright había explicado que prometer lo prohibido está en sí mismo prohibido. Así, una de las leyes deónticas sobre el compromiso se basaba en la tautología deóntica (-Pq \& $\mathrm{O}[\mathrm{p}>\mathrm{q}])>-\mathrm{Pp}$ : «Si hacer algo nos compromete a hacer lo que está prohibido, entonces nos está prohibido hacer lo primero» ${ }^{21}$. Ello no significa vulnerar la norma que nos obliga a cumplir nuestras promesas. La confusión estriba en pensar que $-\mathrm{Pq} \& \mathrm{O}(\mathrm{p}>\mathrm{q})$ pudiera implicar $-\mathrm{O}(\mathrm{p}>\mathrm{q})^{22}$. En «An Essay in Deontic Logic and the General Theory of Action», Von Wright vuelve a analizar el problema en el marco de un sistema diádico. En él, O (-t/p) simbolizaría un predicamento: si es el caso que «p», «todos los estados de cosas que pudieran resultar de la acción de un agente están prohibidos», no hay salida permitida. Pero una situación de tal naturaleza es en sí misma una situación prohibida. El predicamento sólo puede surgir «si ha habido un pecado anterior», si el agente ha «caído en una región del árbol de la vida en la que no le está permitido introducirse». Por consiguiente, $O(-t / p)>O-p$ es un teorema. Ello demuestra que el axioma $\mathrm{N} 1 *$ sólo permite predicamentos condicionales, pero no predicamentos absolutos, que no exigen una «caída anterior». Utilizando categorías de Tomás de Aquino, Von Wright destaca que una persona puede estar «perplexus secundum quid» $(\mathrm{O}[-\mathrm{t} / \mathrm{p}])$, pero no «perplexus simpliciter» $(\mathrm{P}[-\mathrm{t} / \mathrm{t}])^{23}$.

7. Retomemos la inapropiada pero deducible inferencia $O(p / q)>-O(-p / r)([19])$. La solución ofrecida por Von Wright para evitar esta inferencia contraintuitiva en el NSDL fue la de sustituir $\mathrm{N} 1$ por $\mathrm{N} 1 *$, manteniendo idénticos los restantes axiomas. Así evitaríamos la implicación [17] y romperíamos la cadena de implicaciones [16]-[19]. Pero, aparentemente, Von Wright no cuestionó que el origen del problema no estuviera en [17], sino en alguna otra implicación. En particular, centremos de nuevo nuestra atención en [16]:

$$
[16] \mathrm{O}(\mathrm{p} / \mathrm{q})>\mathrm{O}(\mathrm{p} / \mathrm{q} \& \mathrm{r})
$$

${ }^{21}$ Von Wright, Georg H., Deontic Logic, cit., págs. 13 y sigs.

${ }^{22}$ Von Wright, George H., An Essay in Modal Logic, North-Holland Publishing Company, Amsterdam, 1951. Utilizo la trad. cast. de A. Demarchi (revisada por E. Bulygin): Ensayo de Lógica Modal, Santiago Rueda, Buenos Aires, 1970, pág. 70 (notas 5 y 6).

${ }^{23}$ Von Wright, Georg H., An Essay in Deontic Logic and the General Theory of Action, North-Holland Publishing Company, Amsterdam, 1968. Utilizo la trad. cast. de E. Garzón Valdés, Un ensayo de lógica deóntica y la teoría general de la acción, UNAM, México, 1976, págs. 96 y sigs. 
Como ya hemos repetido, si ante ciertas circunstancias una cosa es obligatoria, entonces también lo es ante circunstancias lógicamente más fuertes. Si utilizamos «t» como fórmula tautológica tenemos igualmente:

$$
[23] \mathrm{O}(\mathrm{p} / \mathrm{t})>\mathrm{O}(\mathrm{p} / \mathrm{q})
$$

Para cualquier «q», la obligación incondicional de hacer «p» implica la obligación de hacer «p» en las condiciones descritas por «q». [16] y [23] provienen del axioma N3, equivalencia que se puede descomponer en dos implicaciones recíprocas:

$$
\begin{aligned}
& \mathrm{N} 3.1 \mathrm{O}(\mathrm{p} / \mathrm{q}) \& \mathrm{O}(\mathrm{p} / \mathrm{r})>\mathrm{O}(\mathrm{p} / \mathrm{q} \vee \mathrm{r}) \\
& \mathrm{N} 3.2 \mathrm{O}(\mathrm{p} / \mathrm{q} \vee \mathrm{r})>\mathrm{O}(\mathrm{p} / \mathrm{q}) \& \mathrm{O}(\mathrm{p} / \mathrm{r})
\end{aligned}
$$

D. Follesdal y R. Hilpinen han tratado de demostrar que los intentos de Von Wright por superar la paradoja de los «imperativos contrarios-al-deber» fracasan precisamente en virtud de [16] y [23]. La ventaja del sistema diádico parecía a primera vista consistir en que evitaba que, en casos como el ya citado [7]-[10], se pudiesen inferir a la vez Oq y O -q. En el NSDL coexistirían entonces la obligación categórica de realizar la acción comprometida por el deber primario $(\mathrm{O}[\mathrm{q} / \mathrm{t}]$, derivable de $\mathrm{O}[\mathrm{p} / \mathrm{t}]$ y de $\mathrm{O}[\mathrm{p}>\mathrm{q} / \mathrm{t}])$, y la obligación condicionada al incumplimiento del deber primario (O $[-\mathrm{q} / \mathrm{-p}])$. Pero, del mismo modo que hemos enunciado [23], en virtud de N3 podemos enunciar:

$$
[24] \mathrm{O}(\mathrm{q} / \mathrm{t})>\mathrm{O}(\mathrm{q} / \mathrm{-p})
$$

En consecuencia, el NSDL hereda la paradoja, pues persistiría la contradicción, no ya entre $\mathrm{Oq}$ y $\mathrm{O}-\mathrm{q}$, pero sí entre $\mathrm{O}(\mathrm{q} / \mathrm{-p})$ y $\mathrm{O}(-\mathrm{q} / \mathrm{-p})$. Esta inconveniencia ha llevado a algunos autores, entre ellos los citados Follesdal y Hilpinen, a pensar que Von Wright, aunque acertó al poner de manifiesto la necesidad de modificar uno de los tres axiomas del NSDL, erró al decidirse por N1 y no por N3 ${ }^{24}$.

Desde el punto de vista de la teoría semántica de las modalidades deónticas, $\mathrm{O}(\mathrm{p} / \mathrm{q})$ significa que «p» es verdad en todos los mundos ideales de «q»; es decir, en todos los mundos deóntica-

${ }^{24}$ Follesdal, Dagfinn, y Hilpinen, Risto, Deontic Logic: An Introduction, cit., págs. 27 y sigs. 
mente perfectos siempre que «q» sea una verdad lógica. Igualmente, $\mathrm{P}(\mathrm{p} / \mathrm{q})$ significa que «p» es verdad en algunos mundos ideales de «q». Pues bien, conforme a esta teoría, Follesdal y Hilpinen resaltaron que no siempre es válido N3.2; es decir, no siempre ocurre que si «p» es verdad en todos los mundos ideales de ( $\mathrm{q} \vee \mathrm{r}$ ), entonces es también verdad en todos los mundos ideales de «r». Si «r» equivale a «-q», entonces (q v r) equivale a ( $\mathrm{q} v-\mathrm{q})$, es decir, a la tautología «t». En virtud de N3.2, inferiríamos de nuevo [23]: si «p» es verdad en todos los mundos deónticamente perfectos, entonces es verdad en todos los mundos ideales de «q». Pero si «q» es un acto prohibido, entonces «q» es falso en todos los mundos deónticamente perfectos $\mathrm{y}$ «p» puede ser verdad en todos los mundos deónticamente perfectos sin ser verdad en ningún mundo ideal de «q». Por consiguiente, «q» no puede ser un acto prohibido ${ }^{25}$. [23] no es exacto. Debe modificarse en este sentido:

$$
[25] \mathrm{O}(\mathrm{p} / \mathrm{t}) \&-\mathrm{O}(-\mathrm{q} / \mathrm{t})>\mathrm{O}(\mathrm{p} / \mathrm{q})
$$

Y esta modificación exige a su vez la de N3.2:

$$
\mathrm{N} 3.2 * \mathrm{O}(\mathrm{p} / \mathrm{q} \text { v r }) \&-\mathrm{O}(-\mathrm{q} / \mathrm{r}) \&-\mathrm{O}(-\mathrm{r} / \mathrm{q})>\mathrm{O}(\mathrm{p} / \mathrm{q}) \& \mathrm{O}(\mathrm{p} / \mathrm{r})
$$

Parece que la inadecuación de N3 se puede demostrar con un par de ejemplos. Supongamos que un juez que debe decidir la culpabilidad de Juan, presunto homicida, llega a la conclusión de que, en base a las pruebas presentadas, es tan posible que Juan haya cometido el homicidio como que no lo haya cometido. En virtud del principio «in dubio pro reo» absuelve a Juan. Se puede decir entonces que el juez está obligado, en caso de que una persona pueda ser o no ser un homicida, a absolverlo ( $\mathrm{O}[\mathrm{p} / \mathrm{q}$ v r] $)$. Pero esto no implica que entonces tenga a la vez la obligación de absolverlo si fuera verdad que no es el asesino (O $[\mathrm{p} / \mathrm{q}])$, y la obligación de absolverlo si fuera verdad que sí es el asesino $(\mathrm{O}[\mathrm{p} / \mathrm{r}])$, tal como se desprendería de N3.2. Precisamente N3.2* exigiría para que la implicación fuera correcta la compatibilidad entre «q» $\mathrm{y}$ «r», lo cual evidentemente no se produce en este caso, puesto que si es verdad que Juan ha cometido el homicidio no puede ser verdad que Juan no haya cometido el homicidio, ni viceversa.

${ }^{25}$ Ibid., págs. 30 y 31 . 
Igualmente, parece discutible [16], consecuencia directa de N3, según la cual si ante ciertas circunstancias una cosa es obligatoria, entonces también lo es ante circunstancias lógicamente más fuertes. Un ladrón puede tener, ante la circunstancia de haber robado un cuadro de Picasso, la obligación de devolverlo (al margen de su responsabilidad penal). Pero, si además de producir la circunstancia de haber robado un cuadro de Picasso, produce la circunstancia de quemarlo, sería absurdo pensar que entre sus obligaciones se encuentra la de devolverlo. Por consiguiente, una cosa puede ser obligatoria ante determinadas circunstancias $(\mathrm{O}[\mathrm{p} / \mathrm{q}])$ y no por ello serlo ante circunstancias lógicamente más fuertes $(\mathrm{O}$ [p/ q \& r]). Para que esto sea cierto, debe ser el caso que «r» no implique «-p». Como consecuencia de N3.2*, [16] se modificaría en el siguiente sentido:

$$
[26] \mathrm{O}(\mathrm{p} / \mathrm{q}) \&-\mathrm{O}(-\mathrm{p} / \mathrm{r})>\mathrm{O}(\mathrm{p} / \mathrm{q} \& \mathrm{r})
$$

También B. Hansson ha rebatido la decisión de Von Wright de sustituir N1 por N1* para así evitar la inferencia contraintuitiva $\mathrm{O}(\mathrm{p} / \mathrm{q})>-\mathrm{O}(-\mathrm{p} / \mathrm{r})$. En un estudio comparado de los sistemas de Rescher y Von Wright propone un nuevo sistema diádico en el que utiliza $\mathrm{T}$ (f) como conjunto de los mundos posibles en los que «f» es verdad, «t» como conjunto de todos los mundos posibles (tautología), «k» como negación de un teorema (contradicción) y $B_{t}$ como base lógica para la teoría $T$ si y sólo si $\mathrm{T}$ se compone de las fórmulas $\mathrm{f}-$, de tal modo que sea verdad que $B_{t}$ pertenece a «f». Con esta formalización, $\mathrm{N} 1$ es $-\mathrm{O}(\mathrm{k} / \mathrm{f}), \mathrm{N} 1$ * es $-\mathrm{O}(\mathrm{k} / \mathrm{t}), \mathrm{N} 2$ es $\mathrm{O}(\mathrm{f} \& \mathrm{~g} / \mathrm{h}) \leftrightarrow \mathrm{O}(\mathrm{f} / \mathrm{h}) \& \mathrm{O}(\mathrm{g} / \mathrm{h}), \mathrm{N} 3.1$ es $\mathrm{O}(\mathrm{f} / \mathrm{g}) \& \mathrm{O}(\mathrm{f} / \mathrm{h})>\mathrm{O}(\mathrm{f} / \mathrm{g} \& \mathrm{~h})$, $\mathrm{N} 3.2$ es $\mathrm{O}(\mathrm{f} / \mathrm{g} \mathrm{v} \mathrm{h})>\mathrm{O}(\mathrm{f} / \mathrm{g}) \& \mathrm{O}(\mathrm{f} / \mathrm{h}), \mathrm{y} \mathrm{N} 3.2 *$ es $\mathrm{O}(\mathrm{f} / \mathrm{g} \vee \mathrm{h}) \&-\mathrm{O}(-\mathrm{g} / \mathrm{h}) \&-\mathrm{O}(-\mathrm{h} / \mathrm{g})>\mathrm{O}$ $(\mathrm{f} / \mathrm{g}) \& \mathrm{O}(\mathrm{f} / \mathrm{h})^{26}$.

N1 no se cumpliría si existiera un predicamento, aunque si este predicamento no fuera absoluto sí se cumpliría N1*. En expresión de Hansson, sólo si $\mathrm{O}$ (k/f) es verdad, «f» es una circunstancia anormal. Si hay al menos una circunstancia anormal y aceptamos $\mathrm{N} 1 *$, entonces el conjunto $\mathrm{T}$ de todos los contrarios de circunstancias anormales es una teoría consistente. $\mathrm{Si}$ « $\mathrm{f} » \mathrm{y}$ «g» están en $\mathrm{T}$, entonces es verdad $\mathrm{O}(\mathrm{k} /-\mathrm{f})$ y $\mathrm{O}(\mathrm{k} /-\mathrm{g})$, y, por consiguiente, es verdad $\mathrm{O}(\mathrm{k} / \mathrm{f} \mathrm{v}-\mathrm{g})$ y $\mathrm{O}(\mathrm{k} /-[\mathrm{f} \& \mathrm{~g}])$. Si f > g, entonces $\mathrm{O}(\mathrm{k} / \mathrm{-f})$, en virtud de N3.2, implica $\mathrm{O}(\mathrm{k} / \mathrm{-g})$. «k» no está en $\mathrm{T}$ porque «t» es normal por $\mathrm{N} 1 *$, por lo que $\mathrm{T}$ es

${ }^{26}$ Hansson, Bengt, An Analysis of Some Deontic Logics, cit., págs. 124 y sigs. 
consistente. «f» es normal en cuanto que su complemento «-f» no esté en T. Ahora bien, si pensamos en las cuatro fórmulas $\mathrm{f} \& \mathrm{~g}, \mathrm{f} \&-\mathrm{g}$, -f \& $\mathrm{g}$ y -f \& -g, una de ellas debe ser verdad, debe formar una circunstancia no anormal. Y si «f» $\mathrm{y}$ 《g» son lógicamente independientes, lo son los componentes de las cuatro fórmulas, de forma que «hay una serie de circunstancias lógicamente independientes, tal que cualquier cosa que sea obligatoria ante una de ellas está permitida ante la otra». Así pues, si una obligación condicionada a «f» es independiente de una obligación condicionada a «g», entonces $\mathrm{f} \& \mathrm{~g}$ tiene que ser anormal, lo cual contradice no sólo N1 sino también N1*. Hansson apunta que Von Wright consideraba una ventaja la posible existencia de conflictos de deberes derivada de la sustitución de $\mathrm{N} 1$ por $\mathrm{N} 1 *$, pero porque no advirtió que de la combinación de $\mathrm{N} 1$ * con N2 y N3 puede resultar que de un conflicto de deberes se infiera que cualquier cosa es obligatoria $^{27}$.

8. En el apartado 2 he distribuido en dos grupos las soluciones ofrecidas para resolver la paradoja de los «imperativos contrarios-al-deber». El primero de ellos, que hacía referencia a la construcción de un sistema diádico de lógica deóntica precisamente basado en la condicionalidad de las obligaciones, así como a las propuestas de modificación de alguno de los axiomas de dicho sistema, ha sido ya tratado. A continuación aludiré al segundo grupo de soluciones, podría decirse que «externas» en relación con el sistema presentado por Von Wright hasta finales de los años sesenta. Comenzaré analizando la posición de Castañeda, que hace hincapié en la necesidad de un análisis detallado del lenguaje empleado en los enunciados deónticos, para posteriormente mencionar las consecuencias en el problema que estudiamos de sistemas de lógica deóntica «temporalizados» o «gradualizados». Finalmente, prestaré atención a la evolución teórica de Von Wright al respecto a partir de 1968.

En uno de los trabajos más rigurosos de los últimos años sobre las paradojas de la lógica deóntica, «The Paradoxes of Deontic Logic: The Simplest Solution to All of Them in One Fell Swoop», Castañeda comienza citando los dos objetivos a los que debe dirigirse la lógica deóntica: a) la clarificación de los criterios para obtener razonamientos válidos relacionados con obligaciones, deberes, prohibiciones, derechos, etc...; b) la profundización en la estructura lógica del lenguaje ordinario a través del cual nos referimos a dicho conjunto de materias. El cál-

${ }^{27}$ Ibid., págs. 137 y sigs. 
culo deóntico debe ser, por tanto, posterior a la indagación exhaustiva en los datos lingüísticos ${ }^{28}$.

En concordancia con estas pautas, dos son los factores que, en opinión de Castañeda, pueden explicar la inexistencia de consecuencias paradójicas en relación con los «Imperativos contrarios-al-deber». El primero de ellos es útil para desentrañar las razones reales de todas las paradojas: la distinción entre «propositions» («proposiciones») y «practitions» («practiciones»). El segundo es específico para las paradojas sobre obligaciones condicionales: la inexistencia en el idioma inglés -y pienso que tampoco en el español- de una partícula apropiada para expresar una obligación condicional.

En cuanto al primer factor, Castañeda llama la atención sobre el hecho de que frecuentemente no distinguimos la dualidad existente en una misma acción, que puede ser considerada a la vez como una circunstancia y como un foco deóntico. Considerada como una circunstancia, la acción se enuncia lingüísticamente a través de una proposición. Considerada como un foco deóntico, la acción se enuncia lingüísticamente a través de una practición $^{29}$.

En cuanto al segundo factor, Castañeda destaca que partículas condicionales inglesas como «if», «when», «only if», «only in the cas that», «if and only if», «just in case that»..., etc., no expresan correctamente practiciones condicionales. Estas pueden manifestarse en su forma lógica, mediante > o mediante $\supset$, pero no en su forma gramatical, salvo que transformemos la obligación condicional en una obligación disyuntiva (not... or) ${ }^{30}$. Pienso que podemos trasladar estas objeciones a la partícula condicional «si» y a otras análogas del idioma español. Volvamos al ejemplo citado al comienzo de este trabajo:

[B] Debe ser el caso que si cumplimos [A] (si socorremos a un accidentado grave llevándolo al hospital) ignoremos las señales de tráfico con tal de llegar rápido al hospital.

Interpretando equivocadamente la partícula «si» podríamos pensar que estamos realmente ante una «practición condicional», de forma que [B] sería equivalente a la practición disyuntiva:

${ }^{28}$ Castañeda, Hector-Neri, The Paradoxes of Deontic Logic: The Simplest Solution to All of Them in One Fell Swoop, vol. cit. New Studies in Deontic Logic, págs. 37 y 38.

${ }^{29}$ Ibid., págs. 45 y sigs.

${ }^{30}$ Ibid., págs. 43 y 44 y 56 a 58. 
[E] Debe ser el caso que hagamos lo siguiente: no cumplir [A] o ignorar las señales de tráfico con tal de llegar rápido al hospital.

Es evidente que [E] implica:

[F] Si debe ser el caso que cumplamos [A], entonces debe ser el caso que ignoremos las señales de tráfico con tal de llegar rápido al hospital.

[B] se simbolizaría erróneamente como $\mathrm{O}(\mathrm{p}>\mathrm{q})$, [E] como O (-p v q) y [F] como Op > Oq. Así, al mal interpretar «si» obtendríamos el efecto paradójico de que $\mathrm{O}(\mathrm{p}>\mathrm{q})$ implicaría Op > Oq, al margen de que pudiera ser $-\mathrm{p}$.

La clave de la cuestión reside en que, propiamente, [B] no equivale a [E], sino a $[\mathrm{G}]$ :

[G] Si cumplimos [Al, debe ser el caso que ignoremos las señales de tráfico con tal de llegar rápido al hospital.

[G] sería representado formalmente como $\mathrm{p}>\mathrm{Oq}$; es decir, sería un enunciado mixto que combinaría una proposición con una practición. Conforme a $\mathrm{p}>\mathrm{Oq}$, nunca podríamos inferir $\mathrm{Op}>\mathrm{Oq} . \mathrm{O}(\mathrm{p}>\mathrm{q})>(\mathrm{Op}>\mathrm{Oq})$ exige expresamente que «p»y «q» sean practiciones. Dada la inutilidad de «si» para formar verdaderas obligaciones condicionales, la única manera de lograr una plasmación gramatical de $\mathrm{O}(\mathrm{p}>\mathrm{q})$, sin hacer uso de la disyunción, consistiría en incorporar al enunciado la conectiva >:

[H] Debe ser el caso que: declarar mis bienes al Ministerio de Hacienda > pagar impuestos por mis bienes.

$[\mathrm{H}]$ implica:

[I] Si debe ser el caso que declare mis bienes al Ministerio de Hacienda, debe ser el caso que pague impuestos por mis bienes.

$\mathrm{O}(\mathrm{p}>\mathrm{q})$ implica $\mathrm{Op}>\mathrm{Oq}$. Pero esto no es paradójico porque, si es el caso que Op, entonces, al margen de que sea «p» o «-p», es el caso que Oq. Por contra, si utilizáramos «si» en vez de > tendríamos:

$\left[\mathrm{H}^{*}\right]$ Debe ser el caso que si declaro mis bienes al Ministerio de Hacienda deba pagar impuestos por mis bienes. 
En esta ocasión es más transparente la confusión que introduce «si». [H*] es falso, porque mi deber de pagar impuestos por mis bienes no depende de que los declare o no.

9. Quizá haya sido R. Thomason quien mejor haya resaltado la trascendencia de basar la lógica deóntica en el factor tiempo. En su opinión, las nociones deónticas son dependientes de factores temporales hasta el punto de que junto a una teoría lógica de la obligación, de la permisión o de la prohibición, es necesario construir una teoría lógica del tiempo, y ello no sólo porque el alcance de las normas varía según las coordenadas temporales sino, sobre todo, por la propia idea de consecuencia lógica en relación con los lenguajes formales que utilizan los operadores deónticos ${ }^{31}$. En concreto, la lógica deóntica se fundaría en un sistema de lógica temporal en el que se pudiera atender a futuras alternativas posibles; es decir, en el que el tiempo no se estructurara linealmente, sino ramificadamente ${ }^{32}$. Esta opción ha sido desarrollada por L. Aqvist y J. Hoepelman a través del sistema DARB, en el que los operadores deónticos se combinan con específicas modalidades temporales: $\oplus$ («será el caso al próximo instante que») y $\ominus$ («ha sido el caso en el último instante que») $)^{33}$. Analicemos la aplicación de DARB en el ejemplo de «imperativo contrario-al-deber» expuesto en la cadena de enunciados [A]-[D]:

En [A]-[D] aludíamos al deber de socorrer y al deber de ignorar o de no ignorar las señales de tráfico según se hubiera o no cumplido el primer deber. Supongamos que estamos conduciendo tranquilamente por la carretera. Nos hallamos entonces en un instante anterior a nuestra decisión de cumplir o no cumplir el deber de socorrer, pues no hemos encontrado ningún accidentado grave. Si lo encontráramos, tras cumplir o dejar de cumplir el deber de socorrer, nos hallaríamos en instantes en los que habríamos de decidir si, en el caso de haber cumplido el deber de socorrer, vamos o no a cumplir el deber de ignorar las señales de tráfico, o si, en el caso de no haber cumplido el deber

${ }^{31}$ Thomason, Richmond H., Deontic Logic as Founded on Tense Logic, comunicación presentada en la «Temple University Conference on Deviant Semantics», diciembre 1970. Editado en el vol. cit. New Studies in Deontic Logic, págs. 165 y 166.

32 Ibid., págs. 167 y sigs. Véase asimismo Mazzarese, Tecla, Antinomie, paradossi, logica deontica, Rivista Internazionale di Filosofia del Diritto, núm. 61, 1984, págs. 455 y 456.

${ }^{33}$ Aqvist, Lennart y Hoepelman, Jaap, Some Theorems About a «Tree» System of Deontic Tense Logic, vol. cit. New Studies in Deontic Logic, págs. 187 y sigs. 
de socorrer, vamos o no a cumplir el deber de no ignorar las señales de tráfico.

Pensemos en la hipótesis de que conduciendo encontramos un accidentado grave. Podemos llamar «t», «t $+1 《 \mathrm{y}$ «t $+2 »$ a los sucesivos espacios temporales. En «t» no hemos decidido aún si socorrer o no al accidentado. En «t +1 » ha sido el caso que lo hemos socorrido o que no lo hemos socorrido, pero todavía no hemos decidido si ignorar o no ignorar las señales de tráfico. En «t +2 » ha sido el caso que, después de haber sido el caso que lo hayamos socorrido o no lo hayamos socorrido, hemos ignorado o no hemos ignorado las señales de tráfico. Mediante un díagrama con estructura de árbol obtenemos cuatro ramas que representan los mundos posibles:

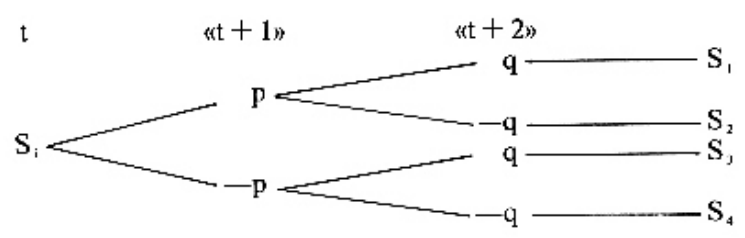

Ante la situación inicial debemos optar por socorrer o no socorrer al accidentado. Posteriormente decidiremos si ignorar o no ignorar las señales de tráfico, tras lo cual nos hallaremos en una de las cuatro situaciones finales posibles. Como ya explicamos, lo paradójico es que si es verdad Op y O $(\mathrm{p}>\mathrm{q})$, es verdad Oq, pero, si -p, entonces también es verdad -Oq. En efecto, sería ilógico pensar que en cualquier caso fuera Oq, porque, si es «p», sí es preferible «q» $\left(\mathrm{S}_{1}\right)$ a «-q» $\left(\mathrm{S}_{2}\right)$, pero si es «-p», es preferible «-q» $\left(\mathrm{S}_{4}\right)$ a «q» $\left(\mathrm{S}_{3}\right)$. En el SDL, [A]-[D] se habría formalizado así:

$$
\begin{aligned}
& {[7] \mathrm{Op}} \\
& {[8] \mathrm{O}(\mathrm{p}>\mathrm{q})} \\
& {[9]-\mathrm{p}>\mathrm{O}-\mathrm{q}} \\
& {[10]-\mathrm{p}}
\end{aligned}
$$

Como antes señalé, el sistema DARB diseñado por Aqvist y Hoepelman incorpora al lenguaje formal deóntico los operadores temporales $\oplus$ («será el caso al próximo instante que») y $\ominus$ («ha sido el caso en el último instante que»). Traduciendo [7]-[10] al sistema DARB obtenemos: 
$[7 \mathrm{a}] \mathrm{O} \oplus \mathrm{p}$

$[8 \mathrm{a}] \mathrm{O} \oplus \mathrm{p}>\oplus \oplus \mathrm{q})$

$[9 \mathrm{a}] \oplus \mathrm{O}-\mathrm{p}>\oplus \mathrm{O} \oplus-\mathrm{q}$

$[10 \mathrm{a}] \oplus-\mathrm{p}$

Lo contradictorio de [7]-[10] era que de [7] y [8] deducíamos Oq, y de [9] y [10] deducíamos O -q. En DARB, de [7a] y [8a] deducimos, y de [9a] y [10a] deducimos $\oplus \mathrm{O}$ $\oplus$-q. $\mathrm{O} \oplus \oplus \mathrm{q} \mathrm{y} \oplus \mathrm{O} \oplus$-q no se contradicen, ya que $\mathrm{O} \oplus \oplus \mathrm{O}$ debe ser ahora que será el caso al próximo instante que») y $\oplus \mathrm{O}$ («será el caso al próximo instante que deberá ser el caso que») son lógicamente independientes entre $\mathrm{si}^{\prime 34}$.

Hemos formulado [7a]-[10a] desde la perspectiva del espacio temporal «t». La inexistencia de la paradoja de los «imperativos contrarios-al-deber» en DARB también se aprecia en $\mathrm{t}+1$ :

[7b] $\ominus \mathrm{O} \oplus \mathrm{p}$

$[8 \mathrm{~b}] \ominus \mathrm{O}(\oplus \mathrm{p} \oplus \oplus \mathrm{q})$

$[9 b]-p>O \oplus-q$

$[10 \mathrm{~b}]-\mathrm{p}$

De [7b] y [8b] deducimos $\ominus \mathrm{O} \oplus \oplus \mathrm{q}$, y de [9b] y [10b] deducimos $\mathrm{O} \oplus$-q, por lo que de nuevo se evita la contradicción ${ }^{35}$. El operador compuesto $\mathrm{O} \oplus$ es lógicamente independiente de $\ominus \mathrm{O} \oplus \oplus$ («ha sido el caso en el último instante que debe ser ahora que será el caso al próximo instante que será el caso al próximo instante»).

Finalmente, desde la perspectiva de $\mathrm{t}+2$ tenemos que:

$[7 \mathrm{c}] \ominus \ominus \mathrm{O} \oplus \mathrm{p}$

$[8 \mathrm{c}] \ominus \ominus \mathrm{O}(\oplus \mathrm{p}>\oplus \oplus \mathrm{q})$

$[9 \mathrm{c}] \ominus-\mathrm{p}>\ominus \mathrm{O} \oplus-\mathrm{p}$

$[10 \mathrm{c}] \ominus-\mathrm{p}$

De [7c] y [8c] deducimos $\ominus \ominus \mathrm{O} \oplus \oplus \mathrm{q}$, y de [9c] y [10c] deducimos $\ominus \mathrm{O} \oplus$-q. Como hemos explicado en relación con $\mathrm{t}+1$, las dos deducciones no son contradictorias, ya que $\ominus \ominus \mathrm{o} \oplus \oplus$ es un operador compuesto lógicamente independiente de $\ominus \mathrm{O} \oplus$.

No quisiera dejar de citar, por su paralelismo con los intentos de solución de la paradoja de los «imperativos contrarios-al-

${ }^{34}$ Ibid., pág. 192.

${ }^{35}$ Ibid., pág. 193. 
deber» que acabamos de exponer, la aproximación al problema que entre nosotros ha realizado L. Peña mediante la extensión del cálculo cuantificacional $A q$ como base del gradualístico y contradictorial sistema de lógica deóntica $A d$. Por lo que a nuestra cuestión afecta, $A d$ es relevante por incorporar símbolos como I («exactamente en la misma medida que»), L («hasta cierto punto», «por lo menos»), K (« [al menos] un poco»), y por diferenciar $\mathrm{N}$ («no») de F («no... en absoluto»). También lo es por su esquema axiomático A10: LdpI $d \mathrm{Lp}$ («el que sea hasta cierto punto obligatorio algo es, ni más ni menos, que sea obligatorio el que hasta cierto punto tenga lugar el algo en cuestión») $)^{36}$.

En $A d$ es cierto el esquema paradójico $d \mathrm{pC} d$ (FpDq) (C es el condicional, D es la implicación y $\mathrm{F}$ es la negación fuerte). Ahora bien, no persiste la paradoja si sustituimos Fp por $\mathrm{Np}$; es decir, si sustituimos la negación fuerte por la negación simple. La razón que ofrece Peña es la siguiente: supóngase que es obligatorio «p», y que en ciertas ocasiones es el caso que «-p». Siendo entonces parcialmente que «p», será y no será verdad su existencia. Pero en modo alguno de ello se infiere que sea obligatoria cualquier cosa. El gradualismo del sistema $A d$ permitiría así que, aunque desde luego fuera absurda toda «supercontradicción» ( $p \& \mathrm{Fp}$ ), no lo fuera forzosamente toda contradicción ( $\mathrm{p} \& \mathrm{~Np})^{37}$. Esta última observación nos hace recordar en cierto sentido la noción de predicamento presentada por Von Wright, que posibilitaba la existencia de conflictos entre obligaciones relativas, aunque no entre obligaciones absolutas.

10. Retornemos la evolución teórica de Von Wright. Sus intentos por lograr una adecuada formalización del compromiso para así solventar las consecuencias paradójicas comentadas han seguido siendo una constante que se refleja en sus trabajos posteriores. En «Deontic Logic and The Theory of Conditions» tra-

${ }^{36}$ Peña, Lorenzo, Un enfoque no-clásico de varias antinomias deónticas, Theoria, núms. 7-8-9, 1987-88, págs. 71 y sigs. Peña reconoce que AIO es el más problemático de los esquemas axiomáticos de Ad. La demostración sería la siguiente: «Supongamos que el que sea obligatorio que en alguna medida suceda tal cosa (?p") sea menos verdadero que el que sea en algún grado obligatorio que ?p". Entonces la obligatoriedad de Lp sería menos verdadera que Lp (pues Lp, cuando sea verdadero, lo será del todo, por su propia naturaleza).» Esta suposición no tiene sentido, por lo que L $d$ p implica $d$ Lp. Del mismo modo, $d$ Lp implica $L d p$. Supongamos que es más o menos verdad que «p». Esto implica que es absolutamente verdad que es obligatorio que «p» (es verdad que $d \mathrm{p}$ ). «Pero entonces es totalmente verdad que $\mathrm{L} d \mathrm{p}$. Y lo totalmente verdadero es implicado por cualquier cosa; entre otras por $d$ Lp.»

${ }^{37}$ Ibid., pág. 89. 
tará de demostrar que las paradojas de la obligación derivada, y en concreto la paradoja de los «imperativos contrarios-al-deber», desaparecen si la lógica deóntica se concibe como teoría lógica condicional. En este artículo no considera la lógica deóntica como análoga inmediata a la lógica modal, sino como un apartado de la Lógica de las Condiciones Suficientes y Necesarias, de tal forma que afirmar que algo debe ser equivale a afirmar que algo es condición necesaria de alguna otra $\operatorname{cosa}^{38}$.

En este sistema de lógica condicional, la noción de condición necesaria se explica así: «la verdad de la proposición que p es condición necesaria de la verdad de la proposición que q». Su representación formal puede ser una de las siguientes:

[27] $\mathrm{Nc}(\mathrm{p}, \mathrm{q})$

$[28] \mathrm{N}(\mathrm{q}>\mathrm{p})$

En efecto, decir que «p» es condición necesaria de «q» significa que si «-p», entonces «-q», o, asimismo, que si «q», entonces necesariamente «p». En términos de condición necesaria, el operador deóntico $\mathrm{O}$ puede ser definido:

$[29] \mathrm{Op}=\mathrm{Nc}(\mathrm{p}, \mathrm{I})$

Que algo debe ser el caso significa que la cosa en cuestión es una condición necesaria de una cierta cosa (proposición, estado de cosas) I, que se presupone en el contexto. I no es una variable sino una constante proposicional ${ }^{39}$.

Por su parte, la noción de condición suficiente se explica así: «la verdad de la proposición que $\mathrm{p}$ es una condición suficiente de la verdad de la proposición que q». $\mathrm{Su}$ representación formal puede ser una de las siguientes:

[30] Sc (p, q)

$[31] N(p>q)$

En efecto, decir que «p» es condición suficiente de «q» significa que si «-q», entonces «-p», o, asimismo, que si «p», entonces necesariamente «q». Se (p, q) equivale a Se $(-q,-p)$, a Nc

${ }^{38}$ Von Wright, Georg H., Deontie Logic and the Theory of Conditions, Crítica, núm, 2, 1968, págs. 3 y sigs. Reeditado en el vol. cit. Deontic Logic: Introductory and Systematic Readings, cit., págs. 159 y sigs.

${ }^{39}$ Ibid. pág. 162. 
(q, p) y a Nc (-p, -q). En términos de condición suficiente, el operador deóntico P puede ser definido:

$$
[32] \mathrm{Pp}=\mathrm{Sc}(\mathrm{p}, \mathrm{I})
$$

Que algo puede ser el caso significa que la cosa en cuestión es una condición suficiente de una cierta cosa I que se presupone en el contexto ${ }^{40}$.

Una condición necesaria puede presentar también forma disyuntiva: «p»o «q» puede ser condición necesaria de «r» (Nc [p v q, r]). Ahora bien, si es el caso que «-p», entonces «q» se convierte en condición necesaria de «r». Esta hipótesis no se puede formular $-\mathrm{p}$ > $\mathrm{Nc}$ (q, r), ya que por el propio concepto de implicación un antecedente falso implica cualquier cosa. Pero parece que sí se podría formular Se (-p, Nc [q, r]), pues «-p» es condición suficiente para que «q» sea condición necesaria de «r». Pensemos ahora que puede ser el caso que no sean ni «p» ni «q» (-N [p v q]). En ese supuesto, sería cierto que si «-p» es condición suficiente para que «q» sea condición necesaria de «r», entonces o «p» $\mathrm{o}\langle\mathrm{q} »$ son condiciones necesarias de $\langle$ r $»$ :

[33] Sc $(-p, N c[q, r] » \&-N(p \vee q)>N c(p \vee q, r)$

Sin embargo, no es cierto:

[34] Nc (p v q, r) \& -N (p v q) > Sc (-p, Nc [q, r])

Si sustituimos «r» por la constante proposicional I, teniendo en cuenta que $\mathrm{Oq}=\mathrm{Nc}$ (q, I), [33] se convierte en:

[35] Sc $(-p, O q) \&-N(p \vee q)>O(p \vee q)$

$\mathrm{O}(\mathrm{p} \vee \mathrm{q})$ puede expresarse condicionalmente como O (-p > q), por lo que Sc (-p, Op) \& -N ( p v q) puede valer como fórmula del compromiso:

[36] Sc (-p, Op) \& -N (-p > q)

Von Wright crea el nuevo operador deóntico condicional Q (q/p), que expresa específicamente la idea de compromiso: «Si está en el agente el poder de producir $\mathrm{p}$, entonces al producir $\mathrm{p}$

${ }^{40}$ Ibid., págs. 164 y 165. 
queda obligado a producir q, a menos que q sea algo que necesariamente se produce si es el caso que $\mathrm{p}$, pues entonces no tiene sentido hablar de obligación». $\mathrm{Q}(\mathrm{q} / \mathrm{p})$ implica $\mathrm{O}(\mathrm{p}$ > $\mathrm{q})$, pero $\mathrm{O}(\mathrm{p}>\mathrm{q})$ no implica $\mathrm{Q}(\mathrm{q} / \mathrm{p})$, por lo que no caben consecuencias paradójicas derivadas de los «imperativos contrarios-al-deber» ${ }^{41}$. Además, al explicar las obligaciones hipotéticas en términos de relaciones condicionales entre proposiciones contingentes, Von Wright subraya que no es forzoso sustituir el axioma N1 por N1*, porque ya no es posible inferir $-\mathrm{O}(-\mathrm{p} / \mathrm{r})$ de $\mathrm{O}(\mathrm{p} / \mathrm{q})^{42}$.

11. Sin arrepentirse de su concepción de la lógica deóntica como fragmento de la teoría lógica modal de las condiciones necesarias y suficientes, concepción que le dirigirá hacia un enfoque «instrumentalista» de la lógica de las normas, Von Wright se centrará pocos años después («Deontic Logic Revisited», 1973) en una distinción hasta entonces muy poco estudiada, resumible mediante las expresiones alemanas «Sein-Sollen» y «Tun-Sollen», respectivamente alusivas a las normas que establecen que tal o cual cosa debe o puede o no debe ser el caso, y a las normas que establecen que alguien debe o puede o no debe hacer tal o cual cosa ${ }^{43}$. Esta distinción provoca una alternativa básica en relación con la cuestión de la naturaleza de la lógica deóntica. Von Wright resalta que la única lógica deóntica construida a partir de la lógica de la acción se ha fundado en interpretaciones de las normas como oraciones descriptivas que acompañan a los operadores deónticos («Es obligatorio o permitido que las cosas se den»). Existiría entonces una lógica deóntica inexplorada, basada en la conjunción de operadores deónticos y verbos de acción, en la que las variables representarían esquemáticamente frases verbales («Es obligatorio o permitido hacer $\mathrm{x} »)^{44}$.

En esta nueva lógica deóntica, la lógica deóntica de las reglas de acción (entendiendo por reglas de acción las expresiones resultantes de la combinación de operadores deónticos y verbos de acción) desaparecerían las principales paradojas deónticas. $O(p)$ no implicaría lógicamente $O(p \vee q)$, por el mero hecho de que (p) x no implicaría lógicamente ( $\mathrm{p} \vee \mathrm{q}) \mathrm{x}$, ya que la acción intencional «Juan lleva la carta al correo» no presupondría en sí misma la acción intencional Juan lleva la carta al correo o la que-

${ }^{41}$ Ibid., págs. 168 y 169.

${ }^{42}$ Ibid., nota 7.

${ }^{43}$ Von Wright, Georg H., Deontic Logic Revisited, Rechstheorie, núm. 4, 1973, pág. 45.

${ }^{44}$ Ibid., págs. 41 y 42. 
ma». Las paradojas serían privativas de la lógica deóntica de las oraciones de acción, como lo demuestra el hecho de que si lo que es obligatorio es que ciertas cosas se den, entonces, si es obligatorio llevar una carta al correo, es obligatorio llevarla al correo o quemarla. Por contra, si lo que es obligatorio es hacer o no hacer determinadas acciones, entonces, si Juan debe llevar la carta al correo, no debe llevar la carta al correo o quemarla, salvo que previamente Juan haya decidido llevarla al correo y no quemarla, y por consiguiente haya tenido lugar una conducta intencional que se podría expresar como $(p \vee q) x^{45}$.

Si en la lógica deóntica de las reglas de acción $O(p)$ no implica $O(p \vee q)$, entonces tampoco podemos inferir $\mathrm{O}(-\mathrm{p} \vee \mathrm{q})$ de $\mathrm{O}-\mathrm{p}$, ni $\mathrm{O}(\mathrm{p}>\mathrm{q})$ de $\mathrm{O}-\mathrm{p}$. Es decir, evitamos las paradojas de la obligación derivada, incluida la paradoja de los «imperativos contrarios-al-deber». En efecto, $\mathrm{O}-\mathrm{p}>\mathrm{O}(\mathrm{p}>\mathrm{q})$ y $\mathrm{Op}>(\mathrm{O}-\mathrm{p}>\mathrm{q})$ son implicaciones válidas en los sistemas estudiados de lógica deóntica, pero porque éstos no apoyaban los operadores deónticos en los verbos de acción. Si así fuera, Op > O (-p > q) sería tan poco válida como $\mathrm{p}(\mathrm{x})>(-\mathrm{p}[\mathrm{x}]>\mathrm{q}[\mathrm{x}])$, puesto que la acción intencional «Juan socorre a un accidentado» no presupondría la acción intencional «Juan no socorre a un accidentado; por lo tanto realiza cualquier otra acción». En la lógica deóntica de las oraciones de acción, en la cual lo que es obligatorio es que ciertas cosas se den, si es obligatorio socorrer a los accidentados, entonces si no se socorre a los accidentados es obligatoria cualquier otra acción. Por contra, en la lógica deóntica de las reglas de acción, en la cual lo que es obligatorio es hacer o no hacer determinadas acciones, si Juan debe socorrer a un accidentado, no debe realizar cualquier otra acción si no lo socorre, salvo que previamente Juan haya decidido realizar cualquier otra acción en razón de que no hubiera socorrido a un accidentado, y por consiguiente haya tenido lugar una conducta intencional que se podría expresar como $(-\mathrm{p}[\mathrm{x}]>\mathrm{q}[\mathrm{x}])$.

12. En los últimos años, el problema de las paradojas quizá no haya sido tan central en los escritos de Von Wright, empeñado especialmente en delimitar algunos conceptos básicos de la lógica de la acción. No obstante, esta labor de perfeccionamiento y delimitación ha repercutido a la hora de volver a enmarcar la temática de las paradojas, al eliminar algunos cabos sueltos y enfocarlas desde perspectivas más precisas.

En «On the Logic of Norms and Actions», Von Wright cues-

${ }^{45}$ Ibid., págs. 44 y sigs. 
tiona seriamente la consideración de los términos deónticos como referidos a las categorías de acciones y no a las acciones individuales, algo que decidiera en «Deontic Logic» (1951) y que ya comenzaría a matizar en «Norm and Action» (1963). Asimismo, vuelve a plantear la interdefinibilidad de los operadores deónticos y, en relación con ello, la posibilidad de admitir normas contradictorias. En cuanto al primer problema, una acción individual («act-individual») podría esquematizarse así: en la ocasión «o», «a» hace «p». No bastaría con citar «o» $\mathrm{y}$ «a», porque un sujeto puede realizar más de una acción en la misma ocasión; es decir, por sí sola, la acción individual no nos proporciona datos definitorios en relación con su contenido. Es necesario aludir a la acción genérica («act-category») «p». Es por ello que a las categorías deónticas interesan tanto las acciones individuales como las acciones genéricas. Es más, la acción genérica en la que se encuentra la acción individual constituye su propiedad esencial. Y dentro de las propiedades de la acción individual también están los atributos deónticos. Si una acción genérica es obligatoria (aquí la categoría deóntica aparece como operador), la realización de la acción genérica por parte de un individuo presupone que la acción individual tiene la propiedad de ser obligatoria (en este caso, la categoría deóntica aparece como predicado) $)^{46}$.

Esta dualidad, según la cual las mismas categorías deónticas se usan como operadores cuando hacen referencia a acciones genéricas, y como predicados cuando hacen referencia a acciones individuales, es de importantes consecuencias. Predicar de una acción individual que está permitida significa que la acción se incluye dentro de una categoría de acciones genéricas permitidas. En este sentido, de la permisión de un cierto tipo de acciones genéricas podemos inferir la no prohibición de dichas acciones, así como la no obligatoriedad de la omisión de las mismas. Ahora bien, si concebimos las categorías deónticas como predicados de acciones individuales no es posible la interdefinibilidad. Una misma acción individual puede ser a la vez obligatoria y prohibida. En el reiterado supuesto de la promesa, su cumplimiento es a la vez obligatorio en virtud de la norma según la cual deben cumplirse las promesas, y prohibido en virtud de que el hecho en cuestión que se ha prometido realizar está prohibido. No hay contradicción, puesto que la acción individual pertenece

${ }^{46}$ Von Wright, Georg H., On the Logic of Norms and Actions, cit., págs. 15 y sigs. 
a la vez a un tipo de acciones que están prohibidas y a un tipo de acciones que son obligatorias $^{47}$. Por consiguiente, sólo si consideramos las categorías deónticas como operadores de acciones genéricas no es compatible la obligatoriedad de una categoría de acciones con la prohibición de la misma categoría de acciones. Pero en una lógica deóntica que relacione actos individuales ni el principio de no contradicción ni la interdefinibilidad de los operadores deónticos se podría articular.

Al comienzo de este trabajo explicábamos que la paradoja de los «imperativos contrarios-al-deber» se debía a que la formulación lógica de este tipo de imperativos era Op \& O (-p > q) («Debe ser ?p"; también debe ser que si no ?p”, ?q”».) La conjunción de estas dos fórmulas entrañaba consecuencias absurdas, pues la existencia de un deber implicaba que de su incumplimiento se derivara «cualquier otro deber». Este «cualquier otro deber» podría ser justamente el «imperativo contrario-al-deber», pero también podría ser otra obligación sin relación con él, e incluso podría consistir en la negación de lo que el «imperativo contrario-al-deber» ordenara. Así, en nuestro ejemplo, tendríamos por un lado que debemos socorrer a todo accidentado grave que encontremos llevándolo al hospital, y además tendríamos que si no cumpliéramos dicha obligación deberíamos no ignorar las señales de tráfico. Pero, por otro lado, el deber de socorrer implicaría que de su incumplimiento se inferiría cualquier otro deber, incluido el deber de ignorar las señales de tráfico en el camino hacia el hospital.

En «Norms, truth and logic» (1983), Von Wright presenta una distinción que, en su opinión, puede esclarecer estas situaciones paradójicas. Se trata de la distinción entre «deber técnico» («must» $\mathrm{y}$ «deber deóntico» («ought»). El deber técnico alude a que alguna cosa «debe ser hecha» para que alguna otra cosa se consiga. Es decir, los deberes técnicos suelen ser elípticos, al referirse implícitamente a un fin que no se logrará si lo que «debe ser» -en sentido técnico- no «es». el deber deóntico es el que emana directamente de una norma; es categórico, no es un medio sino un fín en sí mismo ${ }^{48}$.

Pensemos de nuevo en el ejemplo de la cadena de enunciados [A]-[D], que expresa un «imperativo contrario-al-deber». Lo problemático consistiría en que, por un lado, sería cierto que $\mathrm{O}(\mathrm{p}>\mathrm{q})$, lo que, teniendo en cuenta que también es cierto Op,

${ }^{47}$ Ibid., págs. 23 y sigs.

${ }^{48}$ Von Wright, Georg H., Norme, verita e logica, cit., págs. 31 y 32. 
implicaría Oq. Pero, por otro lado, tenemos que $-\mathrm{p}>\mathrm{O}-\mathrm{q} . \mathrm{O}(\mathrm{p}>\mathrm{q})$ significa que «debe (?ought") ser que, si ?p", ?q". -p > O -q significa que «si es que -p, debe (?must") ser -q». El primer deber es un «deber deóntico», una norma «condicional». El segundo deber es un «deber técnico», una norma «hipotética» ${ }^{49}$. ¿Es esta delimitación suficiente para impedir la persistencia de la paradoja? Parece que no porque, como vimos en 1., podríamos reemplazar $-\mathrm{p}>\mathrm{O}-\mathrm{q}$ por $\mathrm{O}(-\mathrm{p}>-\mathrm{q})$, sin por ello obtener mejores resultados. Tropezaríamos con el escollo de que Op implica $\mathrm{O}(-\mathrm{p}>-\mathrm{q})$, y esta implicación se mantendría incluso si sustituyéramos «-q» por «q»: Op > $\mathrm{O}(-\mathrm{p}>\mathrm{q})$. Pero esta contradicción, para el último Von Wright, no significa incoherencia desde el punto de vista racional, sino simplemente que si Op se viola, el cumplimiento de $\mathrm{O}(-\mathrm{p}>\mathrm{q})$ y de $\mathrm{O}(-\mathrm{p}>-\mathrm{q})$ «impone requisitos contradictorios (en el sentido estrictamente lógico) a los sujetos normativos.» No es este, por tanto, un problema propiamente lógico, porque la implicación normativa es muy distinta de la relación existencial entre las normas. Decir que Op implica a la vez O (-p > q) y O (-p $>-q)$ no significa forzosamente que si la norma Op existe, $\mathrm{O}(-\mathrm{p}>\mathrm{q})$ y $\mathrm{O}(-\mathrm{p}>-\mathrm{q})$ existen también. En estrecha afinidad con las posiciones expresivistas, en especial con la adoptada por Kelsen en la última edición de «Allgemeine Theorie der Normen» ${ }^{50}$ y en «Recht un Logik $\rangle^{51}$, Von Wright parece aceptar tácitamente que dos normas contradictorias, en directa correspondencia con los actos de voluntad de las que emanan, pueden entrar en conflicto sin por ello dejar de ser ambas válidas. «Si las normas en conflicto existen, lo cual puede suceder, es preciso que el legislador modifique la legislación. El lógico no puede ayudarle» ${ }^{52}$.

${ }^{49}$ Ibid., págs. 30 y 31.

${ }^{50}$ Kelsen, Hans, Allgemeine Theorie der Normen, Hans Kelsen institut, recopilación de K. Ringhofer y R. Walter, Viena, 1979. Existe trad. italiana de M. Torre: Teoria generale delle norme, ed. de M. Losano, Giulio Einaudi, Turín, 1985. En especial, véanse las págs. 188 a 190, 267 a 270 y 349 a 388.

${ }^{51}$ Kelsen, Hans, Recht und Logik, Neues Forum, 1965, págs. 421-425 y 495-500. Existe trad. italiana de C. Mancesi (Diritto e logica, vol. Problemi di teoria del diritio, ed. de R. Guastini, II Mulino, Bolonia, 1980, págs. 173-196) y trad. cast. de J. C. Gardella (Derecho y Lógica, vol. Normas jurídicas y análisis lógico, ed. de U. Klug, estudio preliminar de E. Bulygin, Centro de Estudios Constitucionales, Madrid, 1988, págs. 92-120).

${ }^{52}$ Von Wright, Georg H., Norme, verita e logica, cit., págs. 35 y 36. 


\section{BIBLIOGRAFÍA}

Deontic Logic, Mind, núm. 60, 1951, págs. 1-15 (Lógica Deóntica, trad. cast. de J. Rodríguez Marín, Teorema, Valencia, 1979, págs. 25-47).

An Essay in Modal Logic, North-Holland Publishing Company, Amsterdam, 1951 (Ensayo de lógica modal, trad. cast. de A. Demarchi revisada por E. Bulygin, Santiago Rueda, Buenos Aires, 1970).

A Note on Deontic Logic and Derived Obligation, Mind, núm. 65, 1956, págs. 507-509.

Logical Studies, Routledge and Kegan Paul, Londres, 1957.

On Promises, Theoria, núm. 28, 1962, págs. 277-297.

Norm and Action. A Logical Inquiry, Routledge and Kegan Paul, Londres, 1963 (Norma y Acción. Una investigación lógica, trad. cast. de P. García Ferrero, Tecnos, Madrid, 1970).

The Logic of Preference, University Press, Edimburgo, 1963 (La Lógica de la preferencia, trad. cast. de R. Vernengo revisada por E. Bulygin, Eudeba, Buenos Aires, 1967).

A New System of Deontic Logic, Danish Yearbook of Philosophy, núm. 1, 1964, págs. 173-182.

The Foundation of Norms and Normative Statements, vol. The Foundations of Statements and Decisions, Coloquio Internacional de Metodología de la Ciencia (Varsovia, 1961), ed. de K. Ajdukiewicz, Varsovia, 1965, págs. 351-367.

A Correction to a New System of Deontic Logic, Danish Yearbook of Philosophy, núm, 2, 1965, págs. 103-107.

Deontic Logics, American Philosophical Quarterly, núm. 4, 1967, págs. 136-143.

An Essay in Deontic Logic and the General Theory of Action, North Holland Publishing Company, Amsterdam, 1968 (Un ensayo de lógica deóntica y la teoría general de la acción, trad. cast. de E. Garzón Valdés, UNAM, México, 1976).

Deontic Logic and the Ontology of Norms, Actas del 14. ${ }^{\circ}$ Congreso Internacional de Filosofía, Verlag Herder, Viena, 1968, vol. 2, págs. 304-311.

Deontic Logic and the Theory of Conditions, Crítica, núm. 2, 1968, págs. 3-25 (reeditado con algunas modificaciones en el volumen Deontic Logic. Introductory and Systematic Readings, ed. de R. Hilpinen, Reidel, Dordrecht, 1971, págs. 159-177). 
On the Logic and Ontology of Norms, vol. Philosophical Logic, ed. de J. W. Davis y otros, Reidel, Dordrecht, 1969, págs. 89-107.

Deontic Logic Revisited, Rechstheorie, núm. 4, 1973, págs. 37-46 (reencuentro con la lógica deóntica, trad. cast. de E. Bulygin, volumen Derecho, Filosofía y Lenguaje. Homenaje a A. Gioja, Astrea, Buenos Aires, 1976, págs. 225-235; también Nueva visita a la lógica deóntica, trad. cast. de J. Rodríguez Marín, Teorema, Valencia, 1979, págs. 51-67).

On so-called Practical Inference, vol. Practical Reasoning, ed. de J. Raz, Oxford University Press, 1978, págs. 46-62.

Problems and Prospects of Deontic Logic, vol. Modern Logic Asurvay, ed. de E. Agazzi, Reidel, Dordrecht, 1981, págs. 399-423.

On the Logic of Norms and Actions, vol. New Studies in Deontic Logic, ed. de R. Hilpinen, Reidel, Dordrecht, 1981, págs. 3-35.

Norms, Truth, and Logic, vol. Deontic Logic, Computational Linguistics and Legal Information Systems, edición de A. A. Martino, North-Holland Publishing Company, Amsterdam, 1982, págs. 3-20.

Practical Reason. Philosophical Papers I, Basil Blackwell, Oxford, 1983.

Norms of Higher Order, Studia Logica, núm. 42, 1983, págs. 119-127 (Normas de orden superior, trad. cast. de E. Bulygin, vol. El lenguaje del derecho. Homenaje a G. Carrió, Abeledo-Perrot, Buenos Aires, 1983, págs. 457-470).

Is and Ought, vol. Man, Law, and Modern Forms of Life, ed. de E. Bulygin y otros, Reidel, Dordrecht, 1985, págs. 263-281. 